\title{
A Research on the Pile-soil Stress Ratio Range of the Vibroflotation Pile Composite Foundation
}

\author{
Guan Hongjie ${ }^{1.2}$, Dai Yan ${ }^{1}$, Quan Dengzhou ${ }^{1}$ \\ School of Civil Engineering, Chang'an University, Xi'an, Shaanxi Province 710061 \\ Xi'an Eurasia University, Xi'an, Shaanxi Province 710065
}

\begin{abstract}
Keywords: vibroflotation; composite foundation; pile-soil stress ratio; bearing capacity eigenvalue Abstract: The pile-soil stress ratio refers to the ratio between the stress of the pile top and the average stress of the soil among piles. It is an important parameter reflecting the operation status of the composite foundation, as well as a significant index to calculate the bearing capacity and the settlement of the composite foundation. In order to obtain the range of the pile-soil stress ratio of the sand foundation, this paper studies the pile-soil stress ratio based on the data of the static load test for Yulin's project of relocating the airport airfield road. According to the experimental data and the standard formula, this paper makes a back calculation of the ratio (n), and obtains its reasonable range after research, providing a reference for estimating the bearing capacity of the sand foundation. The test proves that the foundation after non-padding vibroflotation treatment has good uniformity, applying to the projects with higher requirements for uneven settlement.
\end{abstract}

\section{Preface}

Vibroflotation method was firstly proposed by German S·STUERMAN in the 1930s. In the 1960s, Japan and other countries in Western Europe, widely applied this technology to consolidate the foundation. In 1977, it was introduced into China ${ }^{[5]}$. Vibroflotation method is used to consolidate sand class foundations. On the one hand, it relies on the strong vibration and water-jetting of the vibroflotation device, to transiently liquefy the sand layer or destroy its structure, which will result in the rearrangement of sand particles and the reduction of pores; on the other hand, it depends on the forced horizontal vibration and compaction effect of the vibroflotation device to make the filling sand (padding from the top of the pore or sand collapsed of itself) dense, thus effectively improving the bearing capacity of the ground ${ }^{[1]}$. The bearing capacity of the composite foundation can be determined by the composite foundation load test, and it also can be estimated by the formula $(1) f_{\text {spk }}=[1+m(n-1)] f_{\text {sk }}{ }^{[3]}$ in the preliminary design stage. This formula is suitable for clay foundation, and this paper applies it for calculating the bearing capacity eigenvalue of sand foundation, with an aim to get a reasonable pile-soil stress ratio range.

In the formula, $n$, the pile-soil stress ratio, refers to the ratio between the stress of the pile top and the average stress of the soil among piles. It is an important parameter reflecting the operation status of the composite foundation, as well as a significant index to calculate the bearing capacity and the settlement of the composite foundation. Due to various causes of the pile-soil stress ratio, its theoretical calculation is much more difficult. Therefore, domestic and foreign scholars put forward different formulas under their respective assumption conditions ${ }^{[2]}$, and the specifications of China ${ }^{[3]}$ only define ranges under different conditions: in case of the preliminary design and calculation of the bearing capacity eigenvalue of the composite foundation, $n$ may take a value from 2 to 4 ; when the original soil is of low and high intensity, $n$ gets 4 and 2 respectively. However, the value of $n$ 
above is only for clay foundation. According to formula (1), when $n$ equals to 2 or 4 , n-1, the coefficient of $\mathrm{m}$, expands twice, so, within this range, the value of $\mathrm{n}$ has a larger impact on the calculation result of the bearing capacity eigenvalue. In addition, the range of $n$ is not given in the specifications of the range of sand foundation ${ }^{[3]}$, therefore, in many areas, there is no principle for calculating the bearing capacity eigenvalue of sand foundation. Based on the engineering test value and formula (1), this paper makes a back calculation of the pile-soil stress ratio, providing a reference for correctly estimating the bearing capacity of the composite foundation and designing economic and reasonable foundation.

\section{Overview of the Project}

Yulin's project of relocating airport airfield covers the construction of runways, contact ways and station sites. With the geomorphic unit of semi-mobile and semi-fixed dune at the edge of Mu Us Desert this project is located in the northwest of Yulin city. The engineering characteristics of the subsoil at the site are as follows:

The first layer is of plain fill: its main component is loose fine sand, belonging to middle or slightly low compressible soil, with the thickness of $0.4 \sim 8.8 \mathrm{~m}$.

The second layer is of fine sand: middle or slightly low compressible soil, with moderate density, and the thickness of $0.5 \sim 17.2 \mathrm{~m}$. The upper of the layer in the excavation area is loose or slightly dense.

The third layer is of silty clay: malleable middle compressible soil, with the maximum thickness of $9.3 \mathrm{~m}$.

According to the geological data, the fluctuation of the original terrain is larger, the regularity of stratigraphic accumulation is poorer, the cause and thickness of the stratum are complex, and the thickness of the excavation and fill in case of site leveling changes a lot, all of which, exacerbate the non-uniformity of the foundation, leading to the loose state and low bearing capacity of the first layer. In view of the geological conditions of Yulin, we can adopt a number of sand foundation treatment methods, such as replacement cushion method, cement mixing pile (wet process) method, vibroflotation sand pile method, cement flyash gravel (CFG) pile method, etc. This project chooses the replacement cushion method and vibroflotation method to consolidate the sand foundation. The replacement cushion method is commonly used to treat the soft foundation and uneven foundation of the superficial layer by excavating the soft foundation soil within a certain range below the foundation, backfilling with good-quality soil, and compacting the soil by layer. This layer will serve as the bearing stratum of the construction ${ }^{[1]}$. This method can improve the foundation bearing capacity and decrease the total settlement of the foundation. Thanks to high efficiency of construction, adjustment of treatment depth and bearing capacity through the spacing, order and length of piles, and obvious improvement of the bearing capacity and good uniformity of the foundation after treatment, vibroflotation water-jetting sand pile is adopted. At present, there are two vibroflotation methods mainly used to consolidate sand class foundations, namely non-padding consolidation and padding consolidation. Consolidating fine sand foundation with padding vibroflotation method, needs large amount of padding, so the project quality is difficult to control and inspect; on the other hand, there is a big argument on whether the uneven settlement problem of the site can be effectively solved. Therefore, for the projects concerning wharf, airport and road, with big consolidation areas and high requirements for uneven settlement, padding vibroflotation method has great limitations. Non-padding vibroflotation method can effectively solve the above problems, and has advantages of simple construction, short duration, and low cost ${ }^{[6]}$, so, non-padding vibroflotation encryption foundation technology is adopted for the foundation 
treatment.

The project sites numbered 1,2, 3 and 4 are located in the excavation area, and the replacement cushion method is used; non-padding vibroflotation method is adopted for sites numbered 5, 6 and 7 in the excavation area and sites numbered 8, 9 and 10 in the fill area. Piles, with a diameter of $0.6 \mathrm{~m}$ and a length of $5.0 \mathrm{~m}$, are arranged in an equilateral triangle. In order to compare the influence of different pile spacings on the compactness of the foundation soil, the pile spacing is set to be $1.2 \mathrm{~m}$ for No. 5 and 8 sites, with $1.5 \mathrm{~m}$ for No. 6 and 9 sites, and $1.8 \mathrm{~m}$ for No. 7 and 10 sites.

\section{Overview of the Test}

One static load test is conducted both on the pile body and piles in No. 10 site. In other sites, two static load tests are conducted for the pile body and piles. A total of 22 static load tests are made, with the maximum load of 500KPa, and no damage occurs during all these tests.

Counterforce device

Weight platform counterforce device is adopted for the test, i.e., I-beams and planks constitute the surcharge load platform, with a bag of about $150 \mathrm{KN}$ on the platform as the counterforce of the weight. Put the load transducer and the main beam of loading on the top of a $500 \mathrm{KN}$ jack, and the circular steel plate with the diameter of $0.60 \mathrm{~m}$ and the area of $0.283 \mathrm{~m}^{2}$ under the jack. In order to eliminate the effect of the loose sand on the settlement amount, prepressing shall be made before the test. The load of prepressing is $15 \mathrm{KPa}$, and the prepressing costs 30 minutes.

The work site has no electricity, so, the generator is used in the test. Bigger voltage fluctuation and several breakdowns on the power supply system of the instrument have certain effects on the test results.

Measuring system:

Pressure measuring system consists of 4 sets of digital dynamometers and BHR-4 500KN load transducers.

Displacement measuring system consists of 8 sets of dial indicators, strong magnetic stands and benchmark steel beams.

Levels of loading and unloading:

The maximum loading capacity is $500 \mathrm{KPa}$, and loading capacity is divided into 11 levels, namely $30,70,100,150,200,300,350,400,450$ and $500 \mathrm{KPa}$. The unloading capacity in sequence is $400,300,200,100$ and $0 \mathrm{KPa}$.

Time reading and stability standards

After the loading at each level, read the settlement in the $10^{\text {th }}, 20^{\text {th }}, 30^{\text {th }}, 45^{\text {th }}, 60^{\text {th }}$ minute, and then read the settlement every 30 minutes. Within 2 consecutive hours, when the settlement is less than $0.1 \mathrm{~mm}$ per hour, the loading at a lower level can be added. The time of load at each level shall be not less than 2 hours.

After the unloading at each level, read and record the resilience value every 30 minutes, and 2 hours later after the unloading of the whole load, read and record the total resilience value.

The test can be terminated in case of any of the following phenomena:

The amount of settlement increases sharply, the soil is squeezed out, or bearing plate surrounding swells obviously (failure condition).

The amount of settlement accumulated is larger than $6 \%$ of the bearing plate's diameter (namely, bigger than $36 \mathrm{~mm}$, failure condition).

The scheduled maximum loading capacity $500 \mathrm{KPa}$ is reached. 


\section{Analysis of Test Results}

Load (P) and settlement (s) curves obtained from the static load test for the pile body and the soil among piles in each site are as follows:

Figure 1 p-s Curves of Static Load Test for Pile Body in No. 5, 6 and 7 Sites

Figure 2 p-s Curves of Static Load Test for Pile Body in No. 8, 9 and 10 Sites
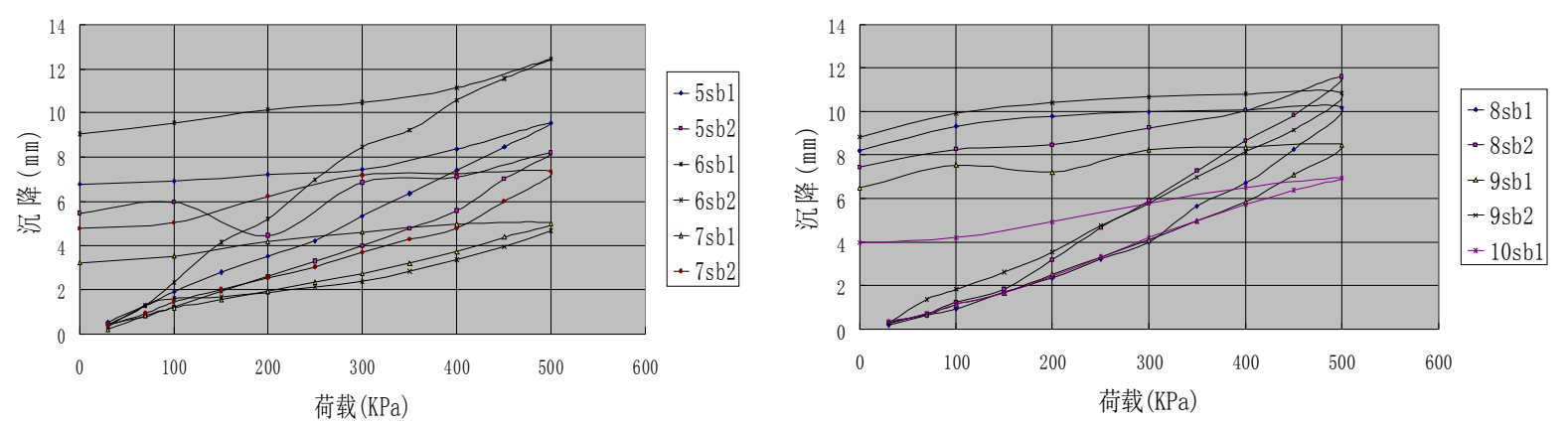

Figure 3 p-s Curves of Static Load Test for Soil among Piles in No. 5, 6 and 7 Sites

Figure 3 p-s Curves of Static Load Test for the Soil among Piles in No. 8, 9, and 10 Sites

According to Figures 1 4, in the process of loading, curve at each test point is gentle and smooth, therefore, the pile-soil bearing capacity eigenvalue ${ }^{[3]}$ is determined by the bearing capacity when s/d equals to 0.01 ( $\mathrm{s}$ refers to the amount of settlement of the bearing plate in the static load test; $d$ refers to the diameter of the bearing plate) (see Table 1). The bearing capacity eigenvalue and the pile-soil stress ratio of the composite foundation can be calculated by the formula in reference [3], and the calculation results are shown in Table 1.

Table 1 Bearing Capacity Eigenvalue \& Pile-soil Stress Ratio of Each Testing Site

\begin{tabular}{|c|c|c|c|c|c|c|c|}
\hline Site & $\mathrm{s}$ & $\mathrm{de}$ & $\mathrm{m}$ & $\mathrm{fpk}$ & $\mathrm{fsk}$ & $\mathrm{fspk}$ & $\mathrm{N}$ \\
\hline 5.1 & 1.2 & 1.8 & 0.111111 & 500 & 332 & 350.6667 & 1.506024 \\
\hline 5.2 & 1.2 & 1.8 & 0.111111 & 417 & 414 & 414.3333 & 1.007246 \\
\hline 6.1 & 1.5 & 2.25 & 0.071111 & 243 & 223 & 224.4222 & 1.089686 \\
\hline 6.2 & 1.5 & 2.25 & 0.071111 & 472 & 500 & 498.0089 & 0.944 \\
\hline 7.1 & 1.8 & 2.7 & 0.049383 & 500 & 500 & 500 & 1 \\
\hline 7.2 & 1.8 & 2.7 & 0.049383 & 500 & 450 & 452.4691 & 1.111111 \\
\hline 8.1 & 1.2 & 1.8 & 0.111111 & 500 & 366 & 380.8889 & 1.36612 \\
\hline 8.2 & 1.2 & 1.8 & 0.111111 & 362 & 304 & 310.4444 & 1.190789 \\
\hline 9.1 & 1.5 & 2.25 & 0.071111 & 428 & 405 & 406.6356 & 1.05679 \\
\hline 9.2 & 1.5 & 2.25 & 0.071111 & 383 & 309 & 314.2622 & 1.239482 \\
\hline 10.1 & 1.8 & 2.7 & 0.049383 & 374 & 420 & 417.7284 & 0.890476 \\
\hline
\end{tabular}

Note: in the table, $\mathrm{s}$ refers to the pile spacing $(\mathrm{m})$; de refers to the diameter $(\mathrm{m})$ of the equivalent-area circle for foundation area processing by root pile, and de equals to $1.5 \mathrm{~s}$; $\mathrm{m}$ refers to the replacement ratio of the pile-soil area, and m equals to $\mathrm{d}^{2} / \mathrm{de}^{2}$; fpk refers to the bearing capacity eigenvalue $(\mathrm{kPa})$ of the pile body; fsk refers to the bearing capacity eigenvalue $(\mathrm{kPa})$ of the soil among piles after processing; fspk refers to the bearing capacity eigenvalue ( $\mathrm{kPa}$ ) of the vibroflotation pile composite foundation; $\mathrm{n}$ refers to the pile-soil stress ratio.

After statistical calculation, the mean of $n$ is 1.127429 , the mean square error $\sigma$ is 0.185481 , and the discreteness of $n$ is smaller. The value of $n$ is closer to 1 , therefore, based on the definition of the pile-soil stress ratio $n$, the average stress difference between the pile body and the soil among piles is smaller, which means that the foundation after non-padding vibroflotation treatment has 
good uniformity. Now, according to formula (1), the bearing capacity eigenvalue of the composite foundation approximately equals to that of the soil among piles after treatment.

According to Table 1, the pile-soil stress ratio is basically in the range of 1 1.5. This result is back-calculated by applying the formula of clay foundation bearing capacity eigenvalue to the sand foundation. The value of $\mathrm{n}$ should be related to the intensity of the original soil. When the intensity is low, $\mathrm{n}$ takes the maximum value, and it takes the minimum value when the intensity is high. Actually, the replacement ratio of the pile-soil area, the length of the pile, the level of the load and the stiffness of the pile, all would affect the value of $n^{[4]}$.

\section{Conclusions}

Through analysis of the test data and researches on the pile-soil stress ratio of the vibroflotation pile composite foundation, we obtain the following results:

The calculation results show that the value of $n$ is close to 1 , which means that the foundation after treatment has good uniformity.

For sand foundation, the pile-soil stress ratio $\mathrm{n}$ may take values from 1 to 1.5 . When the original soil is of low and high intensity, $\mathrm{n}$ takes 1.5 and 1 respectively.

The test shows that the foundation after non-padding vibroflotation treatment has good uniformity, being suitable for projects with higher requirements for uneven settlement.

\section{References}

[1] Foundation Disposal Manual Editorial Committee. Foundation Disposal Manual (the second edition) [M]. Beijing: China Architecture \& Building Press, 2008.

[2] Xue Dianji. Composite Foundation Pile Disposal Technologies. Beijing: China Architecture \& Building Press, 2011.

[3] Technical Specifications of Architectural Foundation Disposal, JGJ 79--2012.

[4] Zhao Minghua, Yang Minghui, Li Lixin, Yao Qiyang. Researches on Analytic Methods of Discrete Materials Composite Foundation Bearing Capacity [J]. Journal of Shenyang Jianzhu University: Science and Technology, 2006, 22(2): 55-58。

[5] Lou Xiaoming, Yu Zhiqiang. A Summary of Current Vibroflotation Method [J]. Journal of Civil Engineering \& Management. 2012, 9(11): 133-136.

[6] Qi Xiulian, Zhou Jian. Experimental Researches and Applications of Non-padding Vibroflotation to Consolidate Silty-fine Sand Foundation [J]. Port Engineering Technology, 2011, 11(8): 77-79. 